\title{
Diabetes incidence in children of different nationalities: an epidemiological approach to the pathogenesis of diabetes
}

\author{
A.Neu, A. Willasch, S. Ehehalt, M. Kehrer, R.Hub, M. B. Ranke \\ University Children's Hospital, Tübingen, Germany
}

\section{Abstract}

Aims/hypothesis. Incidence studies of children with Type I (insulin-dependent) diabetes mellitus and different ethnic backgrounds are known to provide important insights into the pathogenesis of the disease. For this reason, we compared the incidence rate in Baden-Württemberg, Germany, of children who were not of German descent with that of German children as well as with the reported incidence rates pertaining to the countries of origin of the children who were not of German descent.

Methods. Our study was based on the Baden-Württemberg incidence register, part of the EURODIAB TIGER network, which includes 2121 children aged 0-14 years, diagnosed as having Type I diabetes between 1987 and 1997. The study covered a population at risk of 1.8 million children, which represents $13.3 \%$ of the total number of children in Germany.

Results. The total incidence rate was found to be 12.5 per 100000 per year (95\%-CI 12.0-13.0); for German children alone it was calculated as 13.5 (95\%-CI 12.9-14.1) and for children who were not of German descent it was significantly lower at 6.9 per 100000 per year (95\%-CI 5.8-8.0). The percentage of children who were not of German descent with Type I diabetes $(8.3 \%)$ is smaller than that among the general population $(15.2 \%)$. Children from former Yugoslavia, Italy and Greece had incidence rates closer to their countries of origin than to the incidence rate of German children.

Conclusion/interpretation. Our findings indicate that genetic factors play a predominant role in the pathogenesis of Type I diabetes. However, the influence of certain aspects of life-style, which remain constant even after immigration, cannot be excluded. [Diabetologia (2001) 44 [Suppl 3]: B21-B26]

Keywords Diabetes mellitus Type I, diabetes incidence, children, ethnic groups, migration studies, pathogenesis, Germany.
Knowledge of the distribution of a disease in a given population, or in subgroups, leads to a better understanding of its pathogenesis. The large geographical variation in the incidence of Type I (insulin-dependent) diabetes mellitus has generated incidence studies of different ethnic groups to examine the role of genetic and environmental factors in the development of diabetes.

Migration studies have become a classic instrument for analysing the pathogenesis of diabetes on

Corresponding author: Dr. A. Neu, University Children's Hospital, Hoppe-Seyler-Str. 1, D-72076 Tübingen, Germany Abbreviations: BW, Baden-Württemberg; IR, incidence rate. an epidemiological basis [1]. Such studies have, however, led to conflicting results (Table 1 ), which, in turn, make any interpretation of the findings difficult. The variety of methods applied also raises questions about the validity of any comparison between these results. The number of patients analysed in these studies is usually rather small, a source of major criticism. Because only a few studies have been conducted in recent years, the current epidemiological situation is difficult to estimate.

The incidence register of Baden-Württemberg, a federal state in southwest Germany, is part of the EURODIAB TIGER collaborative network and accounts for the highest number of case registrations in 
Table 1. Effects of immigration

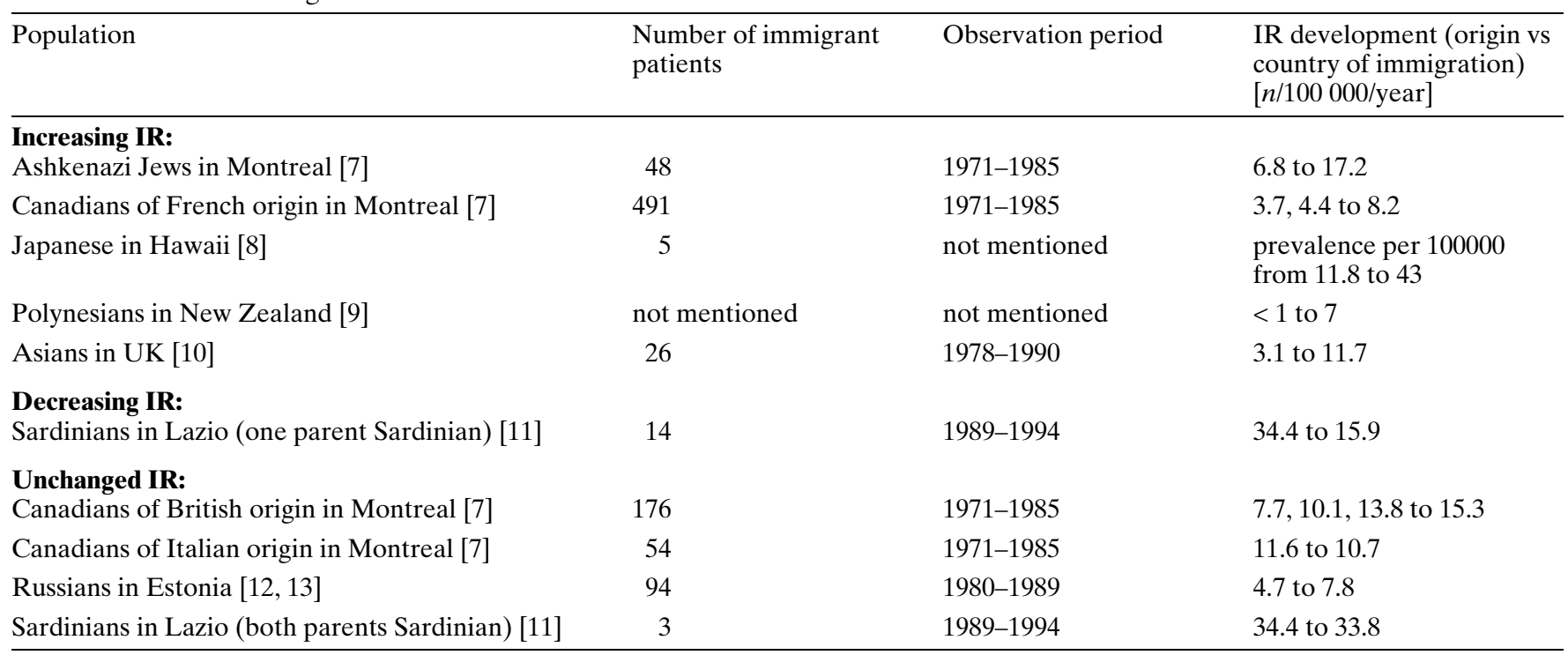

this European research project, which was set up to assess incidence of childhood diabetes Type I in Europe [2]. As the percentage of foreign children in $\mathrm{Ba}-$ den-Württemberg is high, it offers a suitable framework for an analysis of subgroups in the diabetes incidence register.

Our objective was to examine the role of the country of origin and environmental factors in the pathogenesis of diabetes.

\section{Subjects and methods}

Demographic data. Baden-Württemberg is located in the southwest of Germany and covers $35752 \mathrm{~km}^{2}(10.0 \%$ of the total surface area of Germany). Of the total number of 10.4 million inhabitants, $16.9 \%$ (i.e., 1.8 million) are below 15 years of age, which represents to $13.3 \%$ of the total number of children in Germany. A total of $15.2 \%$ of these children hold non-German nationality, $81.6 \%$ of these being from Turkey, the former Yugoslavia, Italy and Greece. Population data was taken from the national census of 1987 and the subsequent official annual updates.

Subjects. At the time of our study, the Baden-Württemberg registry included 2121 children and adolescents under 15 years of age with Type I diabetes. Registration of the patients was done according to the EURODIAB criteria [3] and only included children who started with insulin treatment before their 15 th birthday, with the manifestation of diabetes occurring between 1 January 1987 and 30 June 1997. Because medical care in BadenWürttemberg may also be sought by patients from neighbouring regions and vice versa [4], we included all cases registered in $\mathrm{Ba}$ den-Württemberg in our analysis. We followed the international convention of equating the date of diagnosis with that of the first insulin injection [3]. Nationality was defined according to the passport of each child. At the period covered by our study, German law classified nationality according to descent, i. e. according to a child's parents' nationality (ius sanguinis) and not to the place of birth. This definition of nationality was used both by the Baden-Württemberg registry and the national census.
Data collection and completeness of data. Hospital records were the primary source of data collection. All paediatric departments in Baden-Württemberg $(n=31)$ and one diabetes centre participated in this study, and the 2121 records were examinded by three researchers. A separate, secondary source of data was provided by a questionnaire distributed during meetings of the Diabetic Patients' Association (Deutscher Diabetiker Bund), which was also sent to subscribers of the association's journal. The degree of ascertainment was calculated according to the capture-mark-recapture method $[5,6]$ resulting in $97.2 \%$ for the primary data source and $97.5 \%$ when both data sources were combined.

Standardisation and statistics. Sex and age standardisation of the Baden-Württemberg data was done according to EURODIAB ACE criteria (equal distribution between both sexes and among the three age groups comprising 0-4, 5-9, 10-14 years) [3]. Standardised rates were used for comparisons with data from the literature, depending on availability. The $95 \%$-CI limits were calculated for all incidence rates, assuming a Poisson distribution or - if $n$ was greater than 100 - a normal distribution. Variations in significance were tested by means of an ordinary $\chi^{2}$ (chi square) test (level of significance $\alpha=0.05$ ).

\section{Results}

A total of 2121 newly diagnosed patients aged 0 to 14 years were registered between 1 January 1987 and 30 June 1997 in Baden-Württemberg. The distribution was as follows: 1669 were of German descent, 152 were children in possession of a non-German passport. As patients' nationality was not documented in each hospital, we distributed a number of 25 cases according to the respective proportion of each foreign nationality represented in our registry. The resulting number was termed "corrected". The total incidence rate (standardised for age and sex) was calculated as 12.5 per 100000 per year (95\%-CI 12.0-13.0). The incidence rate for German children 


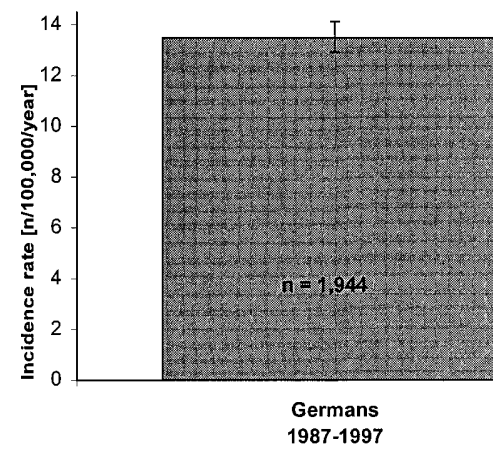

Fig. 1. Incidence rates for German children and children from Mediterranean countries. Germans 1987-1997 $(n=1944)$; Mediterraneans in Germany 1987-1997 $(n=134)$

alone was 13.5 (95\% -CI 12.9-14.1), while for children of non-German descent it was 6.9 per 100000 per year (95\%-CI 5.8-8.0). Thus, the incidence rate for German children proved to be significantly higher $\left(\chi^{2}=77.09, d f=1 ; p<0.0001\right)$ than that for children of non-German descent (Fig. 1).

As mentioned above, non-German nationals account for $15.2 \%$ of the total population of BadenWürttemberg, and $8.3 \%$ of diabetic children in our registry hold non-German nationality. In other words, the diabetic group includes a lower percentage of children of non-German descent than of the total number of children 0-14 years living in Baden-Württemberg.

In the Baden-Württemberg registry, the group of diabetic children from countries other than Germany is made up of 22 nationalities. The four major groups $(75.7 \%)$ comprise children from Mediterranean countries: Turkey $(32.8 \%)$, the former Yugoslavia $(19.8 \%)$, Italy $(16.9 \%)$ and Greece $(6.2 \%)$. Data presented on the number of cases, incidence rate and the $95 \%$-CI for these groups are based on the corrected numbers of patients (including those without documented nationality) (Table 2). Crude numbers and incidence rates are given for comparison: Turkish children $(n=50)$ IR $=4.9(95 \%$-CI 3.6-6.4); Yugoslavian children $(n=30)$ IR $=5.3 \quad(95 \%$-CI 3.6-7.6); Italian children $(n=26)$ IR $=6.8(95 \%$-CI
4.4-9.9); Greek children $(n=9)$ IR $=6.0(95 \%$-CI 2.7-11.4).

We also examined the data to see whether the incidence rate of children of non-German descent was closer to that of their counterparts in their country of origin or to the incidence rate of German children. For this purpose, the incidence rates reported for each country were compared with the Baden-Württemberg incidence rates for children from the former Yugoslavia, Italy and Greece, respectively, but not from Turkey because incidence rates were not available in the literature (Fig. 2-4). The overlap of the confidence intervals shows that the incidence rate of diabetic children among foreigners corresponds to that reported in the respective home country of these children.

\section{Discussion}

An analysis of ethnicity should be based on an extensive number of cases. We used a register with data exceeding 10 years and covering an extremely large base population which, in contrast to previous studies (Table 1), resulted in an analysis based on a very large number of patients (Table 2).

Patients' nationality was not recorded in some of the participating hospitals. Because these gaps in information depended on each hospital and not on the nationality itself, we allocated the small numbers of patients to the ethnic groups according to the proportional distribution of the remainder. With this strategy we avoided a downward bias to the incidence rates. Furthermore, the results remained the same

Table 2. Ethnic distribution of diabetic children in Baden-Württemberg

\begin{tabular}{|c|c|c|c|c|c|}
\hline \multirow{2}{*}{$\begin{array}{l}\text { Children in BW 0-14 years } \\
\text { Total }\end{array}$} & \multirow{2}{*}{$\begin{array}{l}\begin{array}{l}\text { Percent of general } \\
\text { population }\end{array} \\
100.0 \%\end{array}$} & \multicolumn{2}{|c|}{$\begin{array}{l}\text { Number of patients } \\
\text { corrected }\end{array}$} & \multirow{2}{*}{$\begin{array}{l}\text { Incidence rate } \\
{[n / 100000 / \text { year }]} \\
12.5\end{array}$} & \multirow{2}{*}{$\begin{array}{l}\begin{array}{l}95 \%-\mathrm{CI} \\
{[n / 100000 / \text { year }]}\end{array} \\
12.0-13.0\end{array}$} \\
\hline & & 2121 & $100.0 \%$ & & \\
\hline German & $84.8 \%$ & 1944 & $91.7 \%$ & 13.5 & $12.9-14.1$ \\
\hline Turkish & $6.0 \%$ & 58 & $2.7 \%$ & 6.1 & $4.6-7.8$ \\
\hline Yugoslavian & $3.3 \%$ & 35 & $1.7 \%$ & 6.1 & $4.3-8.6$ \\
\hline Italian & $2.2 \%$ & 30 & $1.4 \%$ & 7.9 & $5.3-11.2$ \\
\hline
\end{tabular}




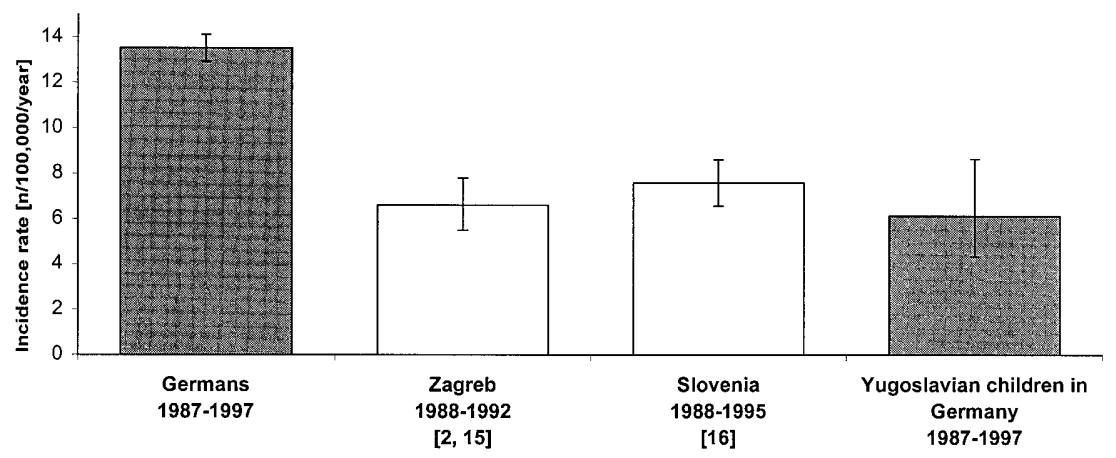

Fig. 2. Specific incidence rates for children from the former Yugoslavia

whether we focused on the raw or on the corrected numbers.

Our investigation is not a migration study in a strict sense: the objective was to compare the data of children of non-German descent living in Germany, according to their nationality, and ascertain their risk of developing diabetes in Germany with the risk in their country of origin. Whether the living conditions of each individual child of non-German descent were similar to those of German children or not is a question that could not be answered definitively. It was also impossible to ascertain whether an individual child resided mainly in Germany or in his or her country of origin, a fact that underscores the limitations of an approach in which nationality is defined exclusively according to passport. This procedure continues, however, to be appropriate as a first step in examining the influence of environmental conditions on the inherent risk of developing diabetes in Germany.

Our findings show that the incidence rate of Type I diabetes for children who were not of German origin analysed in this study was parallel to that of their home countries. There is no doubt that the overall in-

Fig. 3. Specific incidence rates for children from Italy cidence rates in Slovenia, Croatia, continental Italy and Greece are much lower than in the northern areas of Europe [14]. In Baden-Württemberg, the incidence of diabetes of children of Mediterranean origin is significantly lower than that for children of German origin (Fig. 1). Although there is a high degree of heterogeneity among the people inhabiting the Mediterranean coast, the clear differences in the diabetes incidence of children from the Mediterranean compared with children from Germany seems to be attributable to genetic differences.

Our findings also showed minor changes between the incidence rate of children in the country of origin and children after immigration to Germany. When the incidence rate of children not of German descent was compared with that of the respective country of origin, the $95 \%$-CIs showed a remarkable overlap within each ethnic group but differed sharply from the $95 \%$ limits of the German population (Fig. 2-4). In view of the regional variations in each of these countries, we chose to concentrate on a few registries, giving preference to those participating in the EURODIAB TIGER network.

The results of previous studies (Table 1) are conflicting: several researchers reported a rise in the incidence rate occurring after children moved from lowrisk areas to high-risk areas. Others observed that the risk did not differ greatly from that faced in the country of origin, a finding that is reinforced by our results, which bear great similarity to a recently published Sardinian study [11]. Children with Sardinian parents retained the same high incidence rate after emigrating to continental Italy and at no time during the observation period did the risk they faced drop

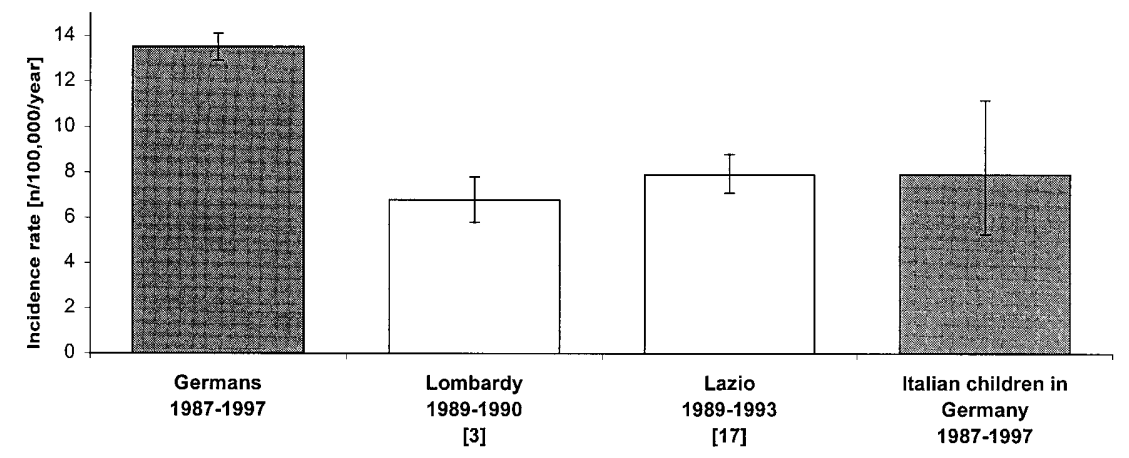




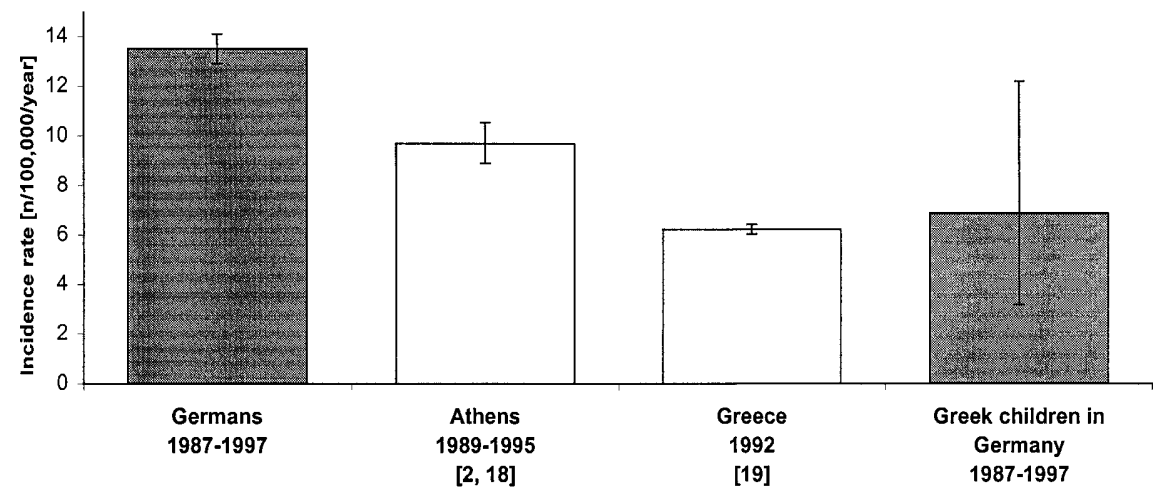

Fig.4. Specific incidence rates for children from Greece

to that prevailing in the new surroundings. The key question is therefore whether an adjustment in incidence rate to that of the local population occurs and not whether the children originally come from lowrisk or high-risk areas.

Although our results suggest that genetic factors predominate in the pathogenesis of diabetes mellitus, we are convinced that it is crucial to consider the environmental factors which remain constant after immigration (e.g. nutritional habits), as they could explain why the incidence continues to be the same even in the country of immigration.

The factor of time is often neglected in comparisons of studies involving ethnicity. Changes in the incidence rate are known to occur within a single generation $[9,10]$ and it cannot be ruled out that major changes become evident long after immigration. It is important to remember that the children of non-German origin living in Baden-Württemberg are first generation immigrants.

The large number of subjects on which our study was based has allowed us to overcome one drawback of migration studies, namely, that the data from small registers was not adequate for such a study. As mentioned, however, the question whether genetic environmental factors predominate in the pathogenesis of diabetes remains open. Studies on the living conditions and habits of the different groups in a given country would be a step forward in this direction.

Acknowledgements. The data presented in this study has been contributed to the data bank of the European Community Concerted Action EURODIAB ACE (Contract no. BMH1CT92-0043) and EURODIAB TIGER (Contract no. BMH4CT96-0577), in which we participated. The study was supported by grants from the foundation "The Diabetic Child" ("Das zuckerkranke Kind").

\section{References}

1. Serrano-Rìos M, Goday A, Martìnez Larrad T (1999) Migrant Populations and the incidence of type 1 diabetes mellitus: an overview of the literature with a focus on the Spanish-heritage countries in Latin America. Diabetes Metab Res Rev 15: 113-132

2. Green A (1999) Review of the annual incidence registration 1996-1999 by centre. EURODIAB TIGER Summary Final Report: 4

3. Green A, Gale EAM, Patterson CC (1992) Incidence of childhood-onset insulin-dependent diabetes mellitus: the EURODIAB ACE study. Lancet 339: 905-909

4. Neu A, Kehrer M, Hub R, Ranke M (1997) Incidence of IDDM in German children aged $0-14$ years. Diabetes Care 20: 530-533

5. LaPorte RE, McCarty DJ, Bruno G, Tajima N, Baba S (1993) Counting diabetes in the next millennium: application of capture-recapture technology. Diabetes Care 16: 528-534

6. LaPorte RE, McCarty DJ, Tull ES, Tajima N (1992) Counting birds, bees and NCDs. Lancet 339: 494-495

7. Siemiatycki J, Colle E, Campbell S, Dewar R, Aubert D, Belmonte MM (1988) Incidence of IDDM in Montreal by ethnic group and social class and comparisons with ethnic groups living elsewhere. Diabetes 37: 1096-1102

8. Tull E, Tajima N, Podar T, Dorman J, Moy C, LaPorte RE (1992) Epidemics, migrants and the death of the pancreas. In: Levy-Marchal C, Czernichow P (eds) Epidemiology and etiology of insulin-dependent diabetes in the young. Pediatr Adolesc Endocrinol, Vol 21. Karger, Basel, pp 56-65

9. Elliott RB (1992) Epidemiology of diabetes in Polynesia and New Zealand. In: Levy-Marchal C, Czernichow P (eds) Epidemiology and etiology of insulin-dependent diabetes in the young. Pediatr Adolesc Endocrinol, Vol 21. Karger, Basel, pp 66-71

10. Bodansky HJ, Staines A, Stephenson C, Haigh D, Cartwright R (1992) Evidence for an environmental effect in the aetiology of insulin dependent diabetes in a transmigratory population. BMJ 304: 1020-1022

11. Muntoni SA, Fonte MT, Stoduto S et al. (1997) Incidence of insulin-dependent diabetes mellitus among Sardinianheritage children born in Lazio region, Italy. Lancet 349: 160-162

12. Podar T, Tuomilehto-Wolf E, Tuomilehto J, LaPorte RE, Adojaan B (1992) Insulin-dependent diabetes mellitus in native Estonians and immigrants to Estonia. Am J Epidemiol 135: 1231-1236

13. Podar T, LaPorte RE, Tuomilehto J, Shubnikov E (1993) Risk of childhood type 1 diabetes for Russians in Estonia and Siberia. Int J Epidemiol 22: 262-267 
14. Muntoni SE, Muntoni SA (1999) New insights into epidemiology of type 1 diabetes in Mediterranean countries. Diabetes Metab Res Rev 15: 133-140

15. Roglić G, Pavlić-Renar I, Šestan-Crnek S et al. (1995) Incidence of IDDM during 1988-1992 in Zagreb, Croatia. Diabetologia 38: 550-554

16. Battelino T, Krzisnik C (1998) Incidence of type 1 diabetes mellitus in children in Slovenia during the years 1988-1995. Acta Diabetol 35: 112-114

17. Sebastiani L, Visalli N, Adorisio E et al. (1996) A 5-year (1989-1993) prospective study of the incidence in Rome and the Lazio Region in the age group 0-14 years. Diabetes Care 19: 70-73

18. Bartsocas CS (1998) Epidemiology of childhood IDDM in Athens: trend in incidence for the years 1989-1995. Diabetologia 41: 245-246

19. Dacou-Voutetakis C, Karavanaki K, Tsoka-Gennatas H, The Hellenic Epidemiology Study Group (1995) National data on the epidemiology of IDDM in Greece. Diabetes Care 18: 552-554 